\title{
Catalyst screening: Refinement of the origin of the volcano curve and its implication in heterogeneous catalysis
}

\author{
Yu Mao a, Jianfu Chen a, Haifeng Wang a,*, P. Hu ${ }^{\mathrm{a}, \mathrm{b}}$ \\ a Key Laboratory for Advanced Materials, Research Institute of Industrial Catalysis and Centre for Computational Chemistry, East China University of \\ Science and Technology, Shanghai 200237, China \\ bSchool of Chemistry and Chemical Engineering, The Queen's University of Belfast Belfast BT9 5AG, United Kingdom
}

\section{A R T I C L E I N F O}

Article history:

Received 1 April 2015

Accepted 27 April 2015

Published 20 September 2015

Keywords:

Volcano curve

Heterogeneous catalysis

Density functional theory

Kinetics

Catalyst screening

Two-step model

\begin{abstract}
A B S T R A C T
Understanding the overall catalytic activity trend for rational catalyst design is one of the core goals in heterogeneous catalysis. In the past two decades, the development of density functional theory (DFT) and surface kinetics make it feasible to theoretically evaluate and predict the catalytic activity variation of catalysts within a descriptor-based framework. Thereinto, the concept of the volcano curve, which reveals the general activity trend, usually constitutes the basic foundation of catalyst screening. However, although it is a widely accepted concept in heterogeneous catalysis, its origin lacks a clear physical picture and definite interpretation. Herein, starting with a brief review of the development of the catalyst screening framework, we use a two-step kinetic model to refine and clarify the origin of the volcano curve with a full analytical analysis by integrating the surface kinetics and the results of first-principles calculations. It is mathematically demonstrated that the volcano curve is an essential property in catalysis, which results from the self-poisoning effect accompanying the catalytic adsorption process. Specifically, when adsorption is strong, it is the rapid decrease of surface free sites rather than the augmentation of energy barriers that inhibits the overall reaction rate and results in the volcano curve. Some interesting points and implications in assisting catalyst screening are also discussed based on the kinetic derivation. Moreover, recent applications of the volcano curve for catalyst design in two important photoelectrocatalytic processes (the hydrogen evolution reaction and dye-sensitized solar cells) are also briefly discussed.
\end{abstract}

(C) 2015, Dalian Institute of Chemical Physics, Chinese Academy of Sciences. Published by Elsevier B.V. All rights reserved.

\section{Introduction}

Rational design/screening of catalysts has long been an important target in heterogeneous catalysis [1-3], since the traditional trial-and-error method is inadequate to meet the demands of the rapid development of the catalyst industry. However, the lack of understanding of the catalytic mechanism at the atomic level greatly limits the efficient design of heteroge- neous catalysts. Fortunately, the popularization of density functional theory (DFT) tools in the past two decades and surface reaction kinetics allows us to theoretically evaluate a catalyst's activity and thus facilitates the overall searching process [1]. Among that, the volcano curve, which was introduced by Balandin [4,5], plays a key role in current descriptor-based catalyst screening framework [6]. Empirically, a volcano-shaped curve (first ascending and then descending) can

\footnotetext{
* Corresponding author. Tel: +086-21-64253453; Fax: +086-21-64253457; E-mail: hfwang@ecust.edu.cn This work was supported by the National Key Basic Research Program of China (2013CB933201), National Natural Science Foundation of China (21303052, 21333003), Fundamental Research Funds for the Central Universities (222201314035), the Commission of Science and Technology of Shanghai Municipality (12ZR1442600), Shanghai Rising-Star Program (14QA1401100) and “Chen Guang” project (13CG24). 


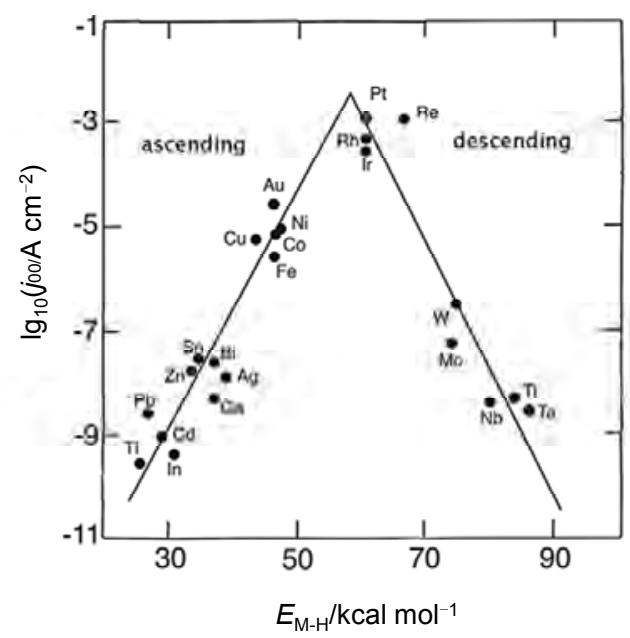

Fig. 1. Trassati's volcano curve for the hydrogen evolution reaction in acid solutions. $\log \left(j_{00}\right)$ denotes the exchange current density while $\mathrm{E}_{\mathrm{M}-\mathrm{H}}$ denotes the energy of hydride formation. Original Fig. in Ref. [8], Copyright 1972, Elsevier. Adapted from Ref. [11]. Copyright 2014, Beilstein-Institut.

usually be obtained upon examining the variation of the catalytic activity for a certain reaction with the position of the transition metals in the periodic table [6,7].

Figure 1 shows a typical volcano curve, which was firstly drawn by Trasatti for the hydrogen evolution reaction (HER) [8]. It is clear that the optimal metal catalyst for the HER is located near the peak of the volcano curve. Scientifically, the volcano curve can serve as a comprehensive basis for understanding the catalytic activities of different catalysts or active sites; technically, it is useful guide in high-throughput screening or design of excellent catalysts $[9,10]$.

This concept, however, did not prevail until the last 10 to 20 years, possibly owing to the lack of understanding about the reaction mechanism at the microscopic level, including the key thermodynamic and kinetic reaction information. Fortunately, the use of DFT calculations and quantum chemical softwares with massively parallel computing techniques facilitates the accumulation of relevant information. Firstly, DFT calculations have become a powerful tool to investigate catalytic processes $[12,13]$. The binding energies of intermediates, reaction barriers, surface structures, and so on can be routinely obtained

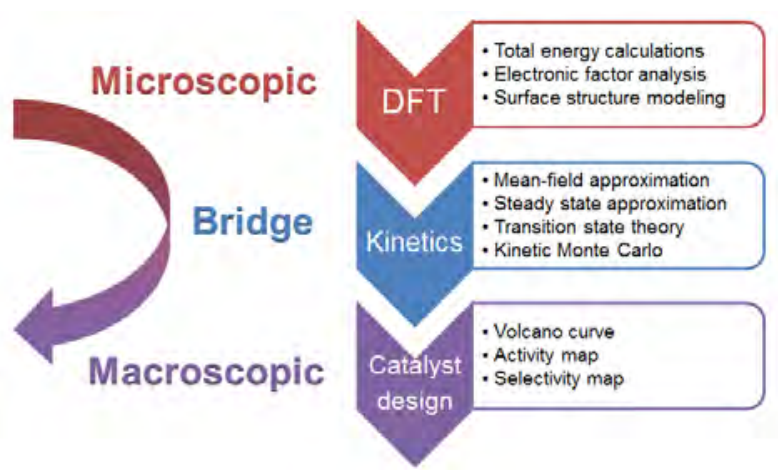

Scheme 1. Illustration of the hierarchical relation among DFT calculations, kinetics, and catalyst design/screening.

with reasonable accuracy. However, some challenges still remain, such as the $a b$ initio simulation of liquid-solid interfaces and proper consideration of the inherent errors in DFT [14,15]. Secondly, with the necessary energies obtained by DFT calculations, kinetic analysis has been increasingly used to assess the performance of catalysts and determine the key rate-limiting factor $[7,16]$. In short, the kinetics serves as a bridge between the macroscopic behavior of catalysts and the microscopic reaction pathways. Scheme 1 illustrates the hierarchical relation among DFT calculations, kinetics, and catalyst design/screening. Nørskov et al. theoretically calculated the rate of ammunition synthesis using the above framework, and the results were within a factor of 3 to 20 of the experimental rate [17]. Their result quantitatively demonstrated the feasibility and reliability of catalyst screening using DFT calculations and kinetics. With these developments, the volcano curve has become the main tool in descriptor-based catalyst screening. Typically, the adsorption energy (or other related parameters) should be located near the peak position of the volcano curve. Such an idea has been successfully applied to many catalytic systems, and has shown to be a simple but powerful approach to assist the theoretical design of catalysts.

The Brønsted-Evans-Polanyi (BEP) relation is a convenient tool to qualitatively analyze the volcano curve for certain catalytic reactions [6,18-24]. There is generally a universal linear relationship between the reaction barrier $E_{\mathrm{a}}$ and the reaction enthalpy $\Delta H$. Based on the BEP relation, Norskov et al. made a significant advance in obtaining the volcano curves of a series

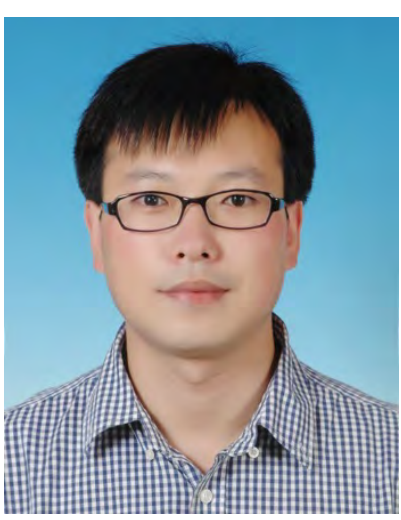

Haifeng Wang (East China University of Science and Technology) received the Rising Star Award in 2014, which was presented by The Catalysis Society of China. Dr. Hai-Feng Wang studied chemistry at East China University of Science and Technology (ECUST) and received Ph.D. degree in 2012. During 2008 to 2010, he did research work in Queen's University Belfast sponsored by China Scholarship Council. After graduation, he joined the Centre for Computational Chemistry in ECUST as an associate professor. His research interests lie in (1) the first principle simulations of heterogeneous catalysts, aiming to clarify the electronic structure and reaction mechanism on gas-solid and liquid-solid interface; (2) developing efficient models for assessment of catalytic activity and rational screening of catalysts; (3) simulation and design of novel electrocatalysts and photocatalysts for renewable energy conversion and solar cells. Currently, he has published more than 30 papers on international peer-reviewed journals, including Nat. Commun., Angew. Chem. Int. Ed., J. Catal. and so on. 
of catalytic reactions, and proposed the "chemical window" concept by exploring the volcano curve: the optimum catalyst should be the catalyst with a binding energy approximately in the range -2 to $-1 \mathrm{eV}$ [19]. Considering the BEP relation, Hu et al. proposed a two-step model to explore the volcano curve taking both adsorption and desorption processes into consideration [25-27]. As well as the BEP relation, the linear scaling relation between surface species further facilitates the process of catalysts screening [28,29]. Interestingly, combining BEP with the scaling relation, 3D volcano curves can be obtained by scaling all of the energies into two surface species [30,31]. For instance, $\mathrm{Hu}$ et al. described a 3D volcano curve of CO hydrogenation by plotting its turnover frequency (TOF) with respect to the chemisorption energies of $\mathrm{C}$ and $\mathrm{O}$, revealing the importance of multiphase catalysts because of some specific scaling relations between surface species [30].

Despite the progress in catalyst design by constructing the volcano curve, some basic issues about the volcano curve are yet to be completely understood. One may ask: what are the important factors that determine the volcano curves in heterogeneous catalysis? What is the essential origin of the volcano curve? Historically, the issue could be understood by the Sabatier principle [32,33], which states that an excellent catalyst should have a moderate binding ability. If adsorption is too weak, reactant will not adsorb on the surface, while if adsorption is too strong, intermediate desorption is difficult. The idea of moderate binding revealed by the Sabatier principle is no doubt illumining. However, the physical picture resulting in the volcano curve mainly relys on experience and commonsense, lacking clear explanation and solid evidence. It has also been suggested that the catalyst surface could be blocked by the intermediates if the binding is too strong, which may slow the overall reaction $[34,35]$. Therefore, to obtain a clear picture of the origin of the volcano curve in heterogeneous catalysis, it is necessary to quantitatively demonstrate and reevaluate the volcano curve. Here, we attempt to carry out a self-consistent kinetic analysis to unveil the essential causes of the volcano curve, as well as the related implications in understanding the activity variation mechanism and assisting catalyst screening.

\section{Establishment of the kinetic model and its expressions}

Including both adsorption and desorption processes, the two-step model is believed to capture the essential of catalytic reactions, and can generally serve as a simplified model to describe the activity trend kinetically [25-27,36]. This model is usually written as

$$
\begin{aligned}
& \text { Adsorption : } \mathrm{R}(g)+* \rightarrow \mathrm{I}^{*} \\
& \text { Desorption: } \mathrm{I}^{*} \rightarrow \mathrm{P}(g)+{ }^{*}
\end{aligned}
$$

where * denotes the free site on the catalyst surface, and R, I, and $\mathrm{P}$ represent the reactant, intermediate, and product, respectively. Fig. 2 shows a schematic illustration of the corresponding energy profile for this model reaction. $E_{\mathrm{ad}, \mathrm{R}}\left(E_{\mathrm{ad}, \mathrm{P}}\right)$ and $E_{\mathrm{R}}{ }^{\text {dis }}\left(E_{\mathrm{P}}\right.$ dis $)$ indicate the reaction enthalpy and energy barrier for the adsorption (desorption) process, which are defined as $E_{\mathrm{ad}, \mathrm{R}}=E_{\mathrm{I}}-E_{\mathrm{R}}$ and $E_{\mathrm{ad}, \mathrm{P}}=E_{\mathrm{I}}-E_{\mathrm{P}}\left(=E_{\mathrm{ad}, \mathrm{R}}-\Delta H\right)$. Generally, they are correlated according to the linear BEP relation:

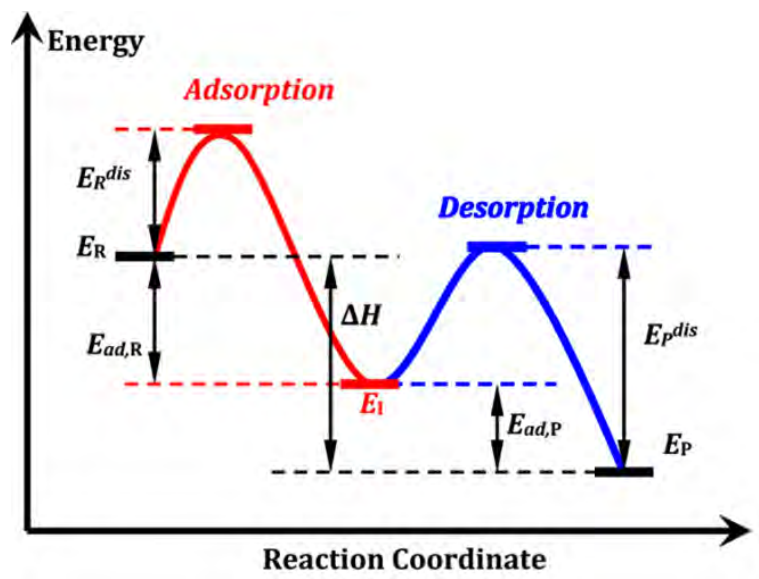

Fig. 2. Schematic illustration of the two-step model and the energetic notations: $\Delta H$ is the enthalpy change of the overall reaction and $E_{X}$ represents the total energy of species $X$. Adapted with permission from Ref. [25]. Copyright 2014, American Chemical Society.

$$
E_{\mathrm{R}}^{\text {dis }}=\alpha_{\mathrm{R}} E_{\mathrm{ad}, \mathrm{R}}+b_{\mathrm{R}} \quad E_{\mathrm{P}}^{\mathrm{dis}}=\alpha_{\mathrm{P}} E_{\mathrm{ad}, \mathrm{P}}+b_{\mathrm{P}}
$$

In other words, $d E^{\mathrm{dis}} / d E_{\mathrm{ad}}=\alpha$. The slope $\alpha$ indicates the reaction type with a limited value between 0 and 1 , while the intercept term $b$ varies with the local configuration of the catalyst surface. For the activity trend of a specific reaction occurring on a similar surface structure, $b$ is a less interesting term.

With these prerequisites, we performed an analytical analysis following the steady state approximation within the microkinetic framework [16], with the aim of revealing the origin of the volcano curve. Based on the De Donder relation $[37,38]$, the reaction rate of each step can be expressed as

$$
r_{1}=k_{1} R^{\prime} \theta_{*}\left(1-z_{1}\right) \quad r_{2}=k_{2} \theta_{\mathrm{I}}\left(1-z_{2}\right)
$$

Here, $\theta_{*}\left(\theta_{\mathrm{I}}\right)$ stands for the coverage of surface free sites (intermediates $) ; z_{i}$ is the reversibility $\left(z_{1}=\theta_{\mathrm{l}} /\left(K_{\text {eq } 1} R^{\prime} \theta_{*}\right)\right.$ and $z_{2}=P^{\prime}$ $\left.\theta_{\sharp} /\left(K_{\mathrm{eq} 2} \theta_{\mathrm{I}}\right)\right)$, which satisfies $Z_{\text {tot }}=z_{1} Z_{2}=P^{\prime} /\left(K_{\mathrm{eq}}{ }^{\text {tot }} R^{\prime}\right) . R^{\prime}$ and $P^{\prime}$ are the relative pressure at the standard state $\left(P_{\mathrm{R}} / P^{\mathrm{o}}, P_{\mathrm{P}} / P^{\circ}\right)$ of the reactant and product, respectively, while $k_{1}\left(k_{2}\right)$ and $K_{\text {eq } 1}\left(K_{\text {eq2 }}\right)$ are the rate constant and equilibrium constant of the adsorption (desorption) process, respectively. Specifically, the rate constant $k$ can usually be obtained by transition state theory:

$$
k=\frac{k_{\mathrm{B}} T}{h} e^{\frac{\Delta S^{*, o}}{R}} e^{\frac{-\Delta H^{*, o}}{R T}}
$$

where $\Delta H^{\neq \neq o}$ and $\Delta S^{\neq, o}$ are the differences of enthalpy and entropy between the transition state and initial state at standard conditions, respectively, and $k_{\mathrm{B}}, h$, and $T$ are the Boltzmann constant, Planck constant, and Kelvin temperature, respectively. It should be noted that the calculated activation and chemisorption energies using DFT are actually the total energy change $(\Delta E)$ at $0 \mathrm{~K}$. To determine of rate constant $k$ at a certain temperature, we apply $\Delta H^{\neq, o} \approx \Delta E$ and the small entropy change term $(\Delta S \neq, o)$ can be ignored for the surface reaction. However, for the adsorption (desorption) process of the gaseous molecule, $\Delta S^{\neq, o}$ must be involved. In the two-step model, this gives

$$
k_{1}=\frac{k_{\mathrm{B}} T}{h} e^{-\frac{E_{\mathrm{R}}^{\mathrm{dis}}+S_{\mathrm{R}} T}{R T}} \quad k_{2}=\frac{k_{\mathrm{B}} T}{h} e^{-\frac{E_{\mathrm{P}}^{\mathrm{dis}}-E_{\mathrm{ad}, \mathrm{P}}}{R T}}
$$

where $S_{\mathrm{R}}\left(S_{\mathrm{P}}\right)$ represents the standard molar entropy of the reactant (product). 
Along with the surface coverage conservation condition $\left(\theta_{*}\right.$ $+\theta_{\mathrm{I}}=1$ ) and Eq.(3), the expression of coverage $\left(\theta_{*}\right)$ and turnover frequency (TOF $=r_{\text {sur }}=r_{1}=r_{2}$ ) under the steady state $\left(d \theta_{I} / d t=r_{1}-r_{2}=0\right)$ can be obtained:

$$
\begin{aligned}
& \theta_{*}=\frac{k_{2}+k_{1} / K_{\mathrm{eq} 1}}{k_{2}+k_{1} / K_{\mathrm{eq} 1}+k_{1} R^{\prime}+k_{2} P^{\prime} / K_{\mathrm{eq} 2}} \\
& r_{\mathrm{sur}}=\frac{k_{1} k_{2} R^{\prime}\left(1-z_{\mathrm{tot}}\right)}{k_{2}+k_{1} / K_{\mathrm{eq} 1}+k_{1} R^{\prime}+k_{2} P^{\prime} / K_{\mathrm{eq} 2}}
\end{aligned}
$$

Applying the BEP relation, the rate would inherently become a function solely depending on $E_{\mathrm{ad}, \mathrm{R}}$ (i.e. $r_{\mathrm{sur}}=f\left(E_{\mathrm{ad}, \mathrm{R}}\right)$ ) for a specific reaction. Then, we can obtain the analytical expression of $r_{\text {sur }}$ with respect to $E_{\mathrm{ad}, \mathrm{R}}$ on the surface:

$$
r_{\text {sur }}=\frac{k_{\mathrm{B}} T}{h} \frac{R^{\prime} e^{\frac{E_{\mathrm{ad}, \mathrm{p}}+S_{\mathrm{p}} T}{R T}}\left(1-z_{t o t}\right)}{e^{\frac{E_{\mathrm{ad}, \mathrm{R}}+E_{\mathrm{P}}^{\text {dis }}+S_{\mathrm{R}} T+S_{\mathrm{P}} T}{R T}}+e^{\frac{E_{\mathrm{add}, \mathrm{P}}+E_{\mathrm{R}}^{\mathrm{dis}}+S_{\mathrm{R}} T+S_{\mathrm{p}} T}{R T}}+R^{\prime} e^{\frac{E_{\mathrm{P}}^{\mathrm{dis}}+S_{\mathrm{P}} T}{R T}}+P^{\prime} e^{\frac{E_{\mathrm{R}}^{\mathrm{dis}}+S_{\mathrm{R}} T}{R T}}}
$$

in which $Z_{\text {tot }}=Z_{1} Z_{2}$, and the reversibility $Z_{1}$ and $z_{2}$ can be obtained for further analysis. Usually, $z_{i} \rightarrow 1$ indicates that step $i$ arrives at equilibrium, while $z_{i} \rightarrow 0$ indicates the step is rate limiting:

$$
\begin{gathered}
z_{1}=\frac{R^{\prime} e^{\frac{\alpha_{\mathrm{p}} E_{\mathrm{ad}, \mathrm{R}}+b_{\mathrm{p}}}{R T}}+P^{\prime} e^{\frac{\alpha_{\mathrm{p}} \Delta H+\alpha_{\mathrm{R}} E_{\mathrm{ad}, \mathrm{R}}+b_{\mathrm{R}}+S_{\mathrm{R}} T-S_{\mathrm{P}} T}{R T}}}{R^{\prime} e^{\frac{\left(\alpha_{\mathrm{p}}-1\right) \Delta H+\alpha_{\mathrm{R}} E_{\mathrm{ad}, \mathrm{R}}+b_{\mathrm{R}}}{R T}}+R^{\prime} e^{\frac{\alpha_{\mathrm{p}} E_{\mathrm{ad}, \mathrm{R}}+b_{\mathrm{P}}}{R T}}} \\
z_{2}=\frac{P^{\prime} e^{\frac{\alpha_{\mathrm{p}} \Delta H+\alpha_{\mathrm{R}} E_{\mathrm{ad}, \mathrm{R}}+b_{\mathrm{R}}}{R T}}+P^{\prime} e^{\frac{\Delta H+\alpha_{\mathrm{p}} E_{\mathrm{ad}, \mathrm{R}}+b_{\mathrm{p}}}{R T}}}{P^{\prime} e^{\frac{\alpha_{\mathrm{p}} \Delta H+\alpha_{\mathrm{R}} E_{\mathrm{ad}, \mathrm{R}}+b_{\mathrm{R}}}{R T}}+R^{\prime} e^{\frac{\alpha_{\mathrm{p}} E_{\mathrm{ad}, \mathrm{R}}+b_{\mathrm{p}}+S_{\mathrm{p}} T-S_{\mathrm{R}} T}{R T}}}
\end{gathered}
$$

To investigate the role of the catalyst surface in the formation of the volcano curve, we also examined a hypothetical gas-phase reaction $\mathrm{R}(\mathrm{g}) \rightarrow \mathrm{I}(\mathrm{g}) \rightarrow \mathrm{P}(\mathrm{g})$, which corresponds to the surface reaction and has the same energy profile as Fig. 2. With similar kinetic derivation, the rate expression in the gas phase $\left(r_{\text {gas }}\right)$ can be obtained:

$$
r_{\text {gas }}=\frac{k_{1} k_{2} R^{\prime}\left(1-z_{\text {tot }}\right)}{k_{2}+k_{1} / K_{\text {eql }}}
$$

It is worth mentioning that such a gas phase reaction may not exist because the energies of gas-phase intermediates are usually higher than those of the reactants, and there may be no evident BEP correlation between $E_{\mathrm{a}}$ and $E^{\text {dis }}$ in the gas phase. However, such a strategy could provide a reference for uncovering the inherent mechanism that controls the activity trend by comparing $r_{\text {sur }}$ and $r_{\text {gas. }}$.

\section{Origin of the volcano curve and implications in catalyst prediction}

\subsection{Proof of the existence of the volcano curve in heterogeneous catalysis and its origin}

To understand the activity trend of heterogeneous catalysis using a fully self-consistent method, we partially differentiated $\ln r_{\text {sur }}$ with respect to $E_{\mathrm{ad}, \mathrm{R}}$ to obtain $\partial \ln r_{\mathrm{sur}} / \partial E_{\mathrm{ad}, \mathrm{R}}$, which will be zero at the maximum activity, resulting in the formation of the volcano curve. Based on Eq.(8), differentiation of the reaction rate can be solved analytically as Eq.(12).

From Eq.(12), $A+B+C+D$ determines the whole variation behavior of $\ln r_{\text {sur, }}$ because the rest of the term is always less than zero. Alternatively, if a volcano curve for $\ln r_{\text {sur }}$ exists (mathematically corresponding to an extreme point), $A+B+C$ $+D$ must equal zero at some point (i.e., $\partial \ln r_{\mathrm{sur}} / \partial E_{\mathrm{ad}, \mathrm{R}}=0$ ). We subsequently prove this in a self-consistent manner. Firstly, at the point we have $(A+D) /(B+C)=-1$, rearranging each term gives the simplified relationship

$$
\frac{\alpha_{\mathrm{R}}+P^{\prime}\left(\alpha_{\mathrm{R}}-1\right) e^{\frac{\Delta H-E_{\mathrm{add}, \mathrm{R}}-S_{\mathrm{P}} T}{R T}}}{\alpha_{\mathrm{P}}+R^{\prime}\left(\alpha_{\mathrm{P}}-1\right) e^{\frac{-E_{\mathrm{ad}, \mathrm{R}}-S_{\mathrm{R}} T}{R T}}}=-e^{\frac{\left(1-\alpha_{\mathrm{p}}\right) \Delta H+\left(\alpha_{\mathrm{P}}-\alpha_{\mathrm{R}}\right) E_{\mathrm{ad}, \mathrm{R}}+b_{\mathrm{p}}-b_{\mathrm{R}}}{R T}}
$$

The right-hand side of Eq.(13) is always less than zero. Therefore, the left-hand side is also less than zero. Solving this inequality, an interesting variation range of $E_{\mathrm{ad}, \mathrm{R}}$ emerges:

$$
\begin{array}{r}
\Delta H-S_{\mathrm{P}} T-R T \ln \frac{\alpha_{\mathrm{R}}}{P^{\prime}\left(1-\alpha_{\mathrm{R}}\right)}<E_{\mathrm{ad}, \mathrm{R}}<-S_{\mathrm{R}} T-R T \ln \frac{\alpha_{\mathrm{P}}}{R^{\prime}\left(1-\alpha_{\mathrm{P}}\right)} \\
\text { or: } \quad-S_{\mathrm{R}} T-R T \ln \frac{\alpha_{\mathrm{P}}}{R^{\prime}\left(1-\alpha_{\mathrm{P}}\right)}<E_{\mathrm{ad}, \mathrm{R}}<\Delta H-S_{\mathrm{P}} T-R T \ln \frac{\alpha_{\mathrm{R}}}{P^{\prime}\left(1-\alpha_{\mathrm{R}}\right)}
\end{array}
$$

These boundaries of the upper inequality can be rearranged as $\mu_{\mathrm{P}}+R T \ln \left[\left(1-\alpha_{\mathrm{R}}\right) / \alpha_{\mathrm{R}}\right]$ and $\mu_{\mathrm{R}}+R T \ln \left[\left(1-\alpha_{\mathrm{P}}\right) / \alpha_{\mathrm{P}}\right]$, which is actually the same as the chemical potential range previously suggested for a good catalyst [25]. With these two boundaries, we will prove that a zero point of $A+B+C+D$ must exist using intermediate value theorem. Here, we choose the upper inequality in Eq.(14) for demonstration. From this inequality:

$$
\Delta H-\left(S_{\mathrm{P}}-S_{\mathrm{R}}\right) T<R T \ln \frac{R^{\prime} \alpha_{\mathrm{R}}\left(1-\alpha_{\mathrm{p}}\right)}{P^{\prime} \alpha_{\mathrm{p}}\left(1-\alpha_{\mathrm{R}}\right)}
$$

Then, at the left boundary, substituting $E_{\mathrm{ad}, \mathrm{R}}=\Delta H-S_{\mathrm{P}} T-$ $R T \ln \left[\alpha_{\mathrm{R}} / P^{\prime} /\left(1-\alpha_{\mathrm{R}}\right)\right]$ into $A+B+C+D\left(\right.$ denoted as $\left.f\left(E_{\mathrm{ad}, \mathrm{R}}\right)\right)$ gives:

$$
f\left(\Delta H-S_{\mathrm{p}} T-R T \ln \frac{\alpha_{\mathrm{R}}}{P^{\prime}\left(1-\alpha_{\mathrm{R}}\right)}\right)=\frac{e^{\frac{\alpha_{\mathrm{p}} \Delta H+b_{\mathrm{p}}-\alpha_{\mathrm{P}} S_{\mathrm{T}} T S_{\mathrm{R}} T}{R R T}}}{\left[\frac{\alpha_{\mathrm{R}}}{P^{\prime}\left(1-\alpha_{\mathrm{R}}\right)}\right]^{\alpha_{\mathrm{P}}}} R^{\prime}\left(1-\alpha_{\mathrm{P}}\right)\left[\frac{P^{\prime} \alpha_{\mathrm{p}}\left(1-\alpha_{\mathrm{p}}\right)}{R^{\prime} \alpha_{\mathrm{R}}\left(1-\alpha_{\mathrm{p}}\right)} e^{\frac{\Delta H-\left(S_{\mathrm{P}}-S_{\mathrm{R}}\right) T}{R T}}-1\right]
$$

Based on Eq.(16), it is not difficult to determine that the last part (in the square brackets) is less than zero, i.e., $f\left(\Delta H-S_{\mathrm{P}} T-\right.$ $\left.R T \ln \left[\alpha_{\mathrm{R}} / P^{\prime} /\left(1-\alpha_{\mathrm{R}}\right)\right]\right)<0$. Furthermore, together with Eq.(12), this indicates that:

$$
\left.\frac{\partial \ln r_{\text {sur }}}{\partial E_{\mathrm{ad}, \mathrm{R}}}\right|_{E_{\mathrm{ad}, \mathrm{R}}=\Delta H-S_{\mathrm{p}} T-R T \ln \frac{\alpha_{\mathrm{R}}}{P^{\prime}\left(1-\alpha_{\mathrm{R}}\right)}}>0
$$

Similarly, on the right boundary, it corresponds to:

$$
\left.\frac{\partial \ln r_{\text {sur }}}{\partial E_{\text {ad, R }}}\right|_{E_{\mathrm{ad}, \mathrm{R}}=-S_{\mathrm{R}} T-R T \ln \frac{\alpha_{\mathrm{P}}}{R^{\prime}\left(1-\alpha_{\mathrm{P}}\right)}}<0
$$

It is a common sense that $r_{\text {sur }}$ should be a continuous function because it describes the real reaction. According to inter-

$$
\begin{gathered}
\frac{\partial \ln r_{\mathrm{sur}}}{\partial E_{\mathrm{ad}, \mathrm{R}}}=\frac{-(A+B+C+D) / R T}{e^{\frac{\left(\alpha_{\mathrm{p}}-1\right) \Delta H+\left(1+\alpha_{\mathrm{R}}\right) E_{\mathrm{ad}, \mathrm{R}}+b_{\mathrm{R}}}{R T}}+e^{\frac{\left(1+\alpha_{\mathrm{P}}\right) E_{\mathrm{add}, \mathrm{R}}+b_{\mathrm{P}}}{R T}}+R^{\prime} e^{\frac{\alpha_{\mathrm{P}} E_{\mathrm{ad}, \mathrm{R}}+b_{\mathrm{p}}-S_{\mathrm{R}} T}{R T}}+P^{\prime} e^{\frac{\alpha_{\mathrm{p}} \Delta H+\alpha_{\mathrm{R}} E_{\mathrm{ad}, \mathrm{R}}+b_{\mathrm{R}}-S_{\mathrm{p}} T}{R T}}} \\
A=\alpha_{\mathrm{R}} e^{\frac{\left(1+\alpha_{\mathrm{R}}\right) E_{\mathrm{ad}, \mathrm{R}}+\left(\alpha_{\mathrm{P}}-1\right) \Delta H+b_{\mathrm{R}}}{R T}} ; B=\alpha_{\mathrm{P}} e^{\frac{\left(1+\alpha_{\mathrm{P}}\right) E_{\mathrm{ad}, \mathrm{R}}+b_{\mathrm{P}}}{R T}} ; C=R^{\prime}\left(\alpha_{\mathrm{P}}-1\right) e^{\frac{\alpha_{\mathrm{P}} E_{\mathrm{ad}, \mathrm{R}}+b_{\mathrm{P}}-S_{\mathrm{R}} T}{R T}} ; D=P^{\prime}\left(\alpha_{\mathrm{R}}-1\right) e^{\frac{\alpha_{\mathrm{R}} E_{\mathrm{ad}, \mathrm{R}}+\alpha_{\mathrm{P}} \Delta H+b_{\mathrm{R}}-S_{\mathrm{P}} T}{R T}}
\end{gathered}
$$


mediate value theorem, there thus must be a zero point for $\partial \ln r_{\mathrm{sur}} / \partial E_{\mathrm{ad}, \mathrm{R}}$ between $\Delta H-S_{\mathrm{P}} T-R T \ln \left[\alpha_{\mathrm{R}} / P^{\prime} /\left(1-\alpha_{\mathrm{R}}\right)\right]$ and $-S_{\mathrm{R}} T$ $-R T \ln \left[\alpha_{\mathrm{P}} / R^{\prime} /\left(1-\alpha_{\mathrm{P}}\right)\right]$. Moreover, because $\partial \ln r_{\mathrm{sur}} / \partial E_{\mathrm{ad}, \mathrm{R}}$ is greater than zero on the left of the zero point, and less than zero on the right, such an extreme point essentially corresponds to a local maximum of $r_{\text {sur. }}$ In other words, plotting $r_{\text {sur }}$ versus $E_{\mathrm{ad}, \mathrm{R}}$ will always lead to a volcano-like curve. It is worth noting that the second situation of Eq.(14) would result in the same conclusion. In short, we have proven the existence of the volcano curve for the heterogeneous catalytic reaction in a completely analytical way.

After proving the existence of the volcano curve, one question naturally arises: how should we determine its origin and what is the key factor determining this phenomenon? To address these issues, we then differentiated $r_{\text {gas }}$ for comparison:

$$
\frac{\partial \ln r_{\mathrm{gas}}}{\partial E_{\mathrm{ad}, \mathrm{R}}}=-\frac{\alpha_{\mathrm{R}} e^{\frac{\alpha_{\mathrm{p}} \Delta H+\alpha_{\mathrm{R}} E_{\mathrm{ad}, \mathrm{R}}+b_{\mathrm{R}}}{R T}}+\alpha_{\mathrm{P}} e^{\frac{\Delta H+\alpha_{\mathrm{P}} E_{\mathrm{ad}, \mathrm{R}}+b_{\mathrm{P}}}{R T}}}{R T\left(e^{\frac{\alpha_{\mathrm{P}} \Delta H+\alpha_{\mathrm{R}} E_{\mathrm{ad}, \mathrm{R}}+b_{\mathrm{R}}}{R T}}+e^{\frac{\Delta H+\alpha_{\mathrm{P}} E_{\mathrm{ad}, \mathrm{R}}+b_{\mathrm{P}}}{R T}}\right)}
$$

It is easy to notice that $\partial \ln r_{\mathrm{gas}} / \partial E_{\mathrm{ad}, \mathrm{R}}$ is always less than zero, indicating a continuously descending reaction rate rather than volcano-like behavior. It is quite surprising that there is no volcano curve for the gas phase reaction while the only difference between $r_{\text {sur }}$ and $r_{\text {gas }}$ is the incorporation of the catalyst in $r_{\text {sur. }}$ To illustrate and verify this result, we subsequently per-

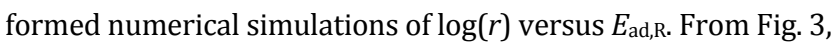
the right-hand sides of the curves are almost identical but the left-hand sides are completely different. For the gas-phase curve, the reaction rate continuously decreases and no peak exists (blue line). However, in the presence of catalyst, $r$ shows a typical volcano-like shape (red line) with a maximum at about $-1.4 \mathrm{eV}$, which is in agreement with chemical window proposed by Nørskov et al. [6]

From the above discussion, both the analytical and numerical results indicate that there is a volcano curve for the catalytic

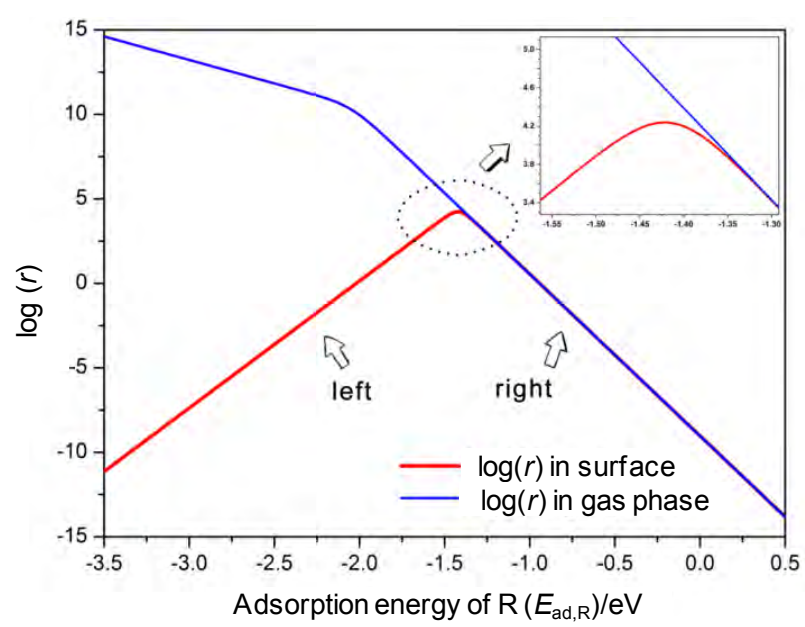

Fig. 3. Numerical simulation of $\log (r)$ versus $E_{\mathrm{ad}, \mathrm{R}}$. The blue and red lines indicate reaction in the gas phase and on the catalyst surface, respectively. The simulation conditions were chosen to model typical industrial catalytic reactions: $\Delta H=-1 \mathrm{eV} ; \alpha_{\mathrm{R}}=0.93 ; \alpha_{\mathrm{P}}=0.27 ; b_{\mathrm{R}}=1.14$; $b_{\mathrm{P}}=0.52 ; P_{a}=P_{b}=1 \mathrm{bar}, T=500 \mathrm{~K}$, and the entropy of reactant and product were set to $2 \mathrm{meV} / \mathrm{K}$. The parameters of the BEP relation were taken from Ref. [27]. reaction but not in the gas phase. If the volcano curve results from a large energy barrier for the intermediate to adsorb or desorb, there is no reason for the volcano curve to disappear in the gas phase. Essentially, it is the decreasing number of free sites on the catalyst surface that results in the left-hand side of the curve being "dragged" down to form a volcano curve (red line). Chemically speaking, the "reaction site" in the gas phase can be deemed to be infinite, thus the volcano curve does not form, while a typical heterogeneous catalytic system usually has a limited number of active sites. This is the reason why on the right-hand side, where the adsorption is weak and there is enough room to accommodate intermediates both on the catalyst surface and in the gas phase, the curves of $r_{\text {gas }}$ and $r_{\text {sur }}$ coincide. For $r_{\text {gas, }}$ the accumulation of intermediates outweighs the augmentation of the desorption barrier, and its value will con-

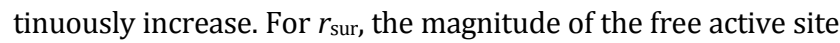
rapidly decreases when $E_{\mathrm{ad}, \mathrm{R}}$ decreases, which is much more pronounced than the increase of the rate constant, making the curve of $r_{\text {sur }}$ bend down on the left-hand side. Therefore, we propose that the self-poisoning effect accompanying heterogeneous catalysis is the fundamental factor that causes the volcano-shaped activity trend.

\subsection{Deeper understanding and implications in guiding catalyst screening}

Interestingly, we can obtain a clearer physical picture of the generation of the volcano curve by further mathematical analysis. From Eqs.(6), (7), and (11), there is a simple relationship between $r_{\text {gas }}$ and $r_{\text {sur: }}$

$$
r_{\text {sur }}=\frac{k_{1} k_{2} R^{\prime}-k_{1} k_{2} P^{\prime} / K_{\text {eq } 1} K_{\text {eq } 2}}{k_{2}+k_{1} / K_{\text {eq } 1}} \frac{k_{2}+k_{1} / K_{\text {eq } 1}}{k_{2}+k_{1} / K_{\text {eq } 1}+k_{1} R^{\prime}+k_{2} P^{\prime} / K_{\text {eq } 2}}=r_{\text {gas }} \theta_{*}
$$

This indicates that $r_{\text {sur }}$ can be simply expressed by $r_{\text {gas }}$ modified by the free sites, further showing the importance of the free sites in determining the activity trend of heterogeneous catalysis. Taking the natural logarithm of both sides, the differential with respect to $E_{\text {ad,R }}$ can be expressed as

$$
\frac{\partial \ln r_{\text {sur }}}{\partial E_{\mathrm{ad}, \mathrm{R}}}=\frac{\partial \ln r_{\mathrm{gas}}}{\partial E_{\mathrm{ad}, \mathrm{R}}}+\frac{\partial \ln \theta_{*}}{\partial E_{\mathrm{ad}, \mathrm{R}}}
$$

We can determine many interesting implications from this expression. Combining Eqs.(9), (10) and introducing the reversibility $z_{1}$ and $z_{2}$, the gas-phase term $\partial \ln r_{\text {gas }} / \partial E_{\text {ad,R }}$ in Eq.(21) can essentially be reformulated as

$$
\frac{\partial \ln r_{\text {gas }}}{\partial E_{\text {ad, R }}}=-\frac{\alpha_{\mathrm{R}}\left(1-z_{1}\right)+\alpha_{\mathrm{p}} z_{1}\left(1-z_{2}\right)}{R T\left(1-z_{\text {tot }}\right)}
$$

Similarly, $\partial \ln \theta_{\star} / \partial E_{\mathrm{ad}, \mathrm{R}}$ can be expressed as

$$
\frac{\partial \ln \theta_{*}}{\partial E_{\text {ad, } \mathrm{R}}}=\frac{\left(1-\theta_{*}\right)}{R T}\left[1+\frac{\left(\alpha_{\mathrm{R}}-\alpha_{\mathrm{P}}\right)\left(1-z_{1}\right)\left(1-z_{2}\right)}{\left(1-z_{\mathrm{tot}}\right)}\right]
$$

With these expressions, we can obtain a deeper insight into the slopes of the curves in Fig. 3. On the far left-hand side, adsorption is strong and desorption would be the rate-limiting step, i.e., $z_{1} \approx 1, z_{2} \approx z_{\text {tot }}$, and $\theta_{*} \approx 0$. Then, the slopes of $\ln r_{\text {sur }}$ and $\ln r_{\text {gas }}$ can be obtained from Eqs.(21)-(23): 


$$
\frac{\partial \ln r_{\text {sur,left }}}{\partial E_{\text {ad, } \mathrm{R}}} \approx \frac{1-\alpha_{\mathrm{P}}}{R T} \quad \frac{\partial \ln r_{\text {gas, left }}}{\partial E_{\text {ad, } \mathrm{R}}} \approx-\frac{\alpha_{\mathrm{P}}}{R T}
$$

Similarly, on the far right-hand side, adsorption is weak and can be regarded as the rate-limiting step, i.e., $z_{1} \approx Z_{\text {tot }}, z_{2} \approx 1$ and $\theta_{*} \approx 1$ :

$$
\frac{\partial \ln r_{\text {sur, right }}}{\partial E_{\text {ad, } \mathrm{R}}} \approx-\frac{\alpha_{\mathrm{R}}}{R T} \quad \frac{\partial \ln r_{\text {gas, right }}}{\partial E_{\text {ad, } \mathrm{R}}} \approx-\frac{\alpha_{\mathrm{R}}}{R T}
$$

One can clearly see that the slope of $\ln r_{\text {right }}$ is the same for the surface and gas-phase reactions, but that of $\ln n_{\text {left }}$ is different. For surface reactions, the slope is negative for $\ln r_{\text {sur,right }}$ and

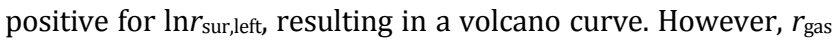
continuously decreases with a different negative slope on both sides $\left(-\alpha_{\mathrm{P}} / R T\right.$ and $\left.-\alpha_{\mathrm{R}} / R T\right)$. These characteristics also agree with the behavior of the curves in Fig. 3. Moreover, Eqs.(22) and (23) can generally be simplified in another way:

$$
\frac{\partial \ln r_{\mathrm{gas}}}{\partial E_{\mathrm{ad}, \mathrm{R}}} \approx-\frac{\alpha}{R T} \quad \frac{\partial \ln \theta_{*}}{\partial E_{\mathrm{ad}, \mathrm{R}}} \approx \frac{\left(1-\theta_{*}\right)}{R T}
$$

in which we assume that $\alpha_{\mathrm{R}}=\alpha_{\mathrm{P}}=\alpha$ for simplicity because $\alpha_{\mathrm{R}}$ and $\alpha_{\mathrm{P}}$ often have a similar magnitude [26]. $\partial \ln r_{\mathrm{gas}} / \partial E_{\mathrm{ad}, \mathrm{R}}$ is a constant, which again accounts for the absence of the volcano curve for the gas-phase reaction. However, $\partial \ln \theta_{\star} / \partial E_{\mathrm{ad}, \mathrm{R}}$ varies with $\theta_{*}$ and remains correlated with $E_{\text {ad,R. Combining Eqs.(21) }}$ and (26) gives

$$
\frac{\partial \ln r_{\mathrm{sur}}}{\partial E_{\mathrm{ad}, \mathrm{R}}}=\frac{\left(1-\theta_{*}\right)}{R T}-\frac{\alpha}{R T}
$$

Quantitatively, $\alpha$ is a constant between 0 and 1 for a given reaction, whereas $\left(1-\theta_{*}\right)$ ranges from 0 (when $E_{\mathrm{ad}, \mathrm{R}}$ is very positive) to 1 (when $E_{\mathrm{ad}, \mathrm{R}}$ is very negative). As a result, $\partial \ln r_{\text {sur }} / \partial E_{\mathrm{ad}, \mathrm{R}}$ will be positive on the left-hand side and negative on the right-hand side, leading to a volcano curve. It seems that the competition between $\partial \ln r_{\mathrm{gas}} / \partial E_{\mathrm{ad}, \mathrm{R}}$ and $\partial \ln \theta_{\star} / \partial E_{\mathrm{ad}, \mathrm{R}}$ leads to a volcano curve, which further emphasizes the role of the incorporation of the surface term $\left(\partial \ln \theta_{\star} / \partial E_{\mathrm{ad}, \mathrm{R}}\right)$. Interestingly, integrating the equation $\partial \ln \theta_{*} / \partial E_{\mathrm{ad}, \mathrm{R}}=\left(1-\theta_{*}\right) / R T$ gives the expression of $\theta_{*}$ with respect to $E_{\mathrm{ad}, \mathrm{R}}: \theta_{*}=1 /\left(1+\exp \left(\left(-E_{\mathrm{ad}, \mathrm{R}}+\right.\right.\right.$ $C) / R T)$ ), where $C$ is a constant. Thus: $\partial \ln \theta_{\sharp} / \partial E_{\mathrm{ad}, \mathrm{R}}=1 /(R T(1+$ $\left.\left.\exp \left(\left(-E_{\mathrm{ad}, \mathrm{R}}+C\right) / R T\right)\right)\right)$, whose value changes from 0 to $1 / R T$ as $E_{\mathrm{ad}, \mathrm{R}}$ changes from being very weak to very strong, indicating that $\ln \theta_{*}$ is nonlinear and rapidly decreases as the adsorption strength increases.

A study of Wang et al [36]. gave a good example to quantitatively understand the conclusion we made above. Choosing NO oxidation as an example, they performed a careful kinetic analysis of the complete reaction. As shown in Fig. 4, the results numerically indicate that $\log (r)$ is determined by the sum of the linear $\log \left(k_{1+}\right)$ and curved $2 \log \left(\theta_{*}\right)$ terms with some simplification, where $k_{1}+$ is the forward rate constant of $\mathrm{O}_{2}$ dissociative adsorption. Additionally, they proposed a method to identify the peak position of $\log (r)$ assuming the slopes of $\log \left(k_{1+}\right)$ and $2 \log \left(\theta_{*}\right)$ to be opposite, suggesting the role of the nonlinear character of $\log \left(\theta_{*}\right)$ in forming the volcano curve, because two straight lines should also give rise to a straight line. Their numerical analysis validates what we analytically determined above. The slope of $\log \left(k_{1+}\right)$ is approximately $-\alpha / R T$ in this circumstance, and the shape of the $\ln \theta *$ curve in Fig. 4 (red line) agrees well with Eq.(26). Here, it is again worth pointing out that, because $\partial \ln \theta_{*} / \partial E_{\mathrm{ad}, \mathrm{R}}$ ranges from 0 to $1 / R T$ (when adsorption is very weak or strong), somewhere in the curve the slope must equal $\alpha / R T$, considering that the value $\alpha$ in the BEP relation is well-known to be in the range $0-1$. In short, the nonlinear character of the $\ln \theta_{*}$ curve can be considered to be an inherent property of heterogeneous catalysis that contributes to the presence of the volcano curve.

More interestingly, from Eq.(27), when $r_{\text {sur }}$ reaches a maximum, we get $\theta_{*}$ opt $=1-\alpha$. With this equation, we can estimate the coverage of active sites for the best catalyst. Typically, if $\alpha \approx$ 0.5 , then $\theta_{*}^{\text {opt }}=0.5$, which agrees with common sense. Similar concepts have been mentioned elsewhere $[26,39,40]$, here we would like to emphasize the implications of this equation $\left(\theta_{*}\right.$ opt $=1-\alpha$ ) in understanding the activity trend for rationally screening catalyst with several examples.

Firstly, this equation might be able to explain why the optimal catalyst is different for ammonia synthesis and its reverse decomposition process. Experimentally, the $\mathrm{N}$ adsorption strength of the optimal catalyst for ammonia synthesis is always higher than that in its decomposition, which has been previously investigated by Boisen et al. and Kozuch et al. $[41,42]$ In our model, this phenomenon can be interpreted as follows. For $\mathrm{NH}_{3}$ synthesis, the dissociative adsorption of $\mathrm{N}_{2}$ is the dominant process. As the value of the parameter $\alpha \approx 0.9$ for $\mathrm{N}_{2}$ dissociation [27], the optimal catalyst should be with $\theta_{*}{ }^{\mathrm{opt}}=$ 0.1 . On the other hand, for $\mathrm{NH}_{3}$ decomposition, $\mathrm{NH}_{3}$ dissociation dominates as its concentration increases and $\alpha \approx 0.3$ [27], corresponding to $\theta_{*}^{\text {opt }}=0.7$. Therefore, it is easy to understand that ammonia synthesis requires an early transition metal (e.g., $\mathrm{Fe}$ and $\mathrm{Ru}$ ) with a strong interaction with $\mathrm{N}_{2}$ to guarantee a small number of free sites [43], while more noble metals (e.g., $\mathrm{Ru}, \mathrm{Co}$, and $\mathrm{Ni}$ ) with less strong adsorption ability, which facili-

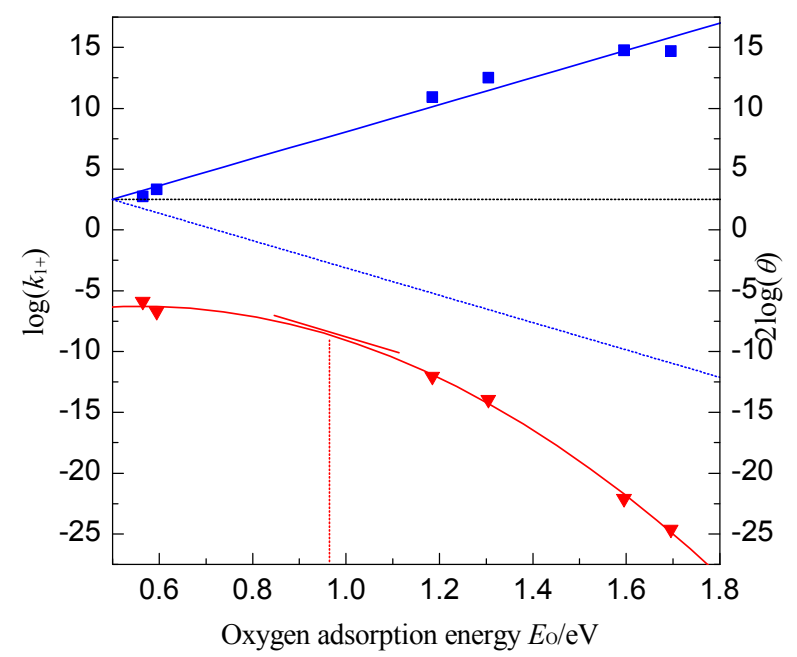

Fig. 4. Decomposition of the volcano curve of NO oxidation. The blue solid line and the red curve correspond to $\log \left(k_{1+}\right)$ and $2 \log \left(\theta_{*}\right)$, respectively. The blue dashed line is symmetrical with the blue solid line. It should be noted that the definition of the adsorption energy here is different from ours (opposite in sign and includes correction of the gas phase entropy). Adapted with permission from Ref. [36]. Copyright 2009, American Institute of Physics. 
tates larger $\theta_{*}$ opt, are more applicable for $\mathrm{NH}_{3}$ dissociation [44].

Secondly, this equation could provide qualitative insight into the origin of different catalytic reactions with a different optimal catalyst. As a specific case, the optimal catalysts for $\mathrm{NH}_{3}$ synthesis and CO methanation are usually early transition metals, while those for $\mathrm{CO}$ or NO oxidation tend to be noble metals. Differing from the first example, the activation of the key reacting species, i.e., diatomic molecular dissociation of $\mathrm{N}_{2}, \mathrm{CO}$, and $\mathrm{O}_{2}$, have been proven to obey the same BEP relation on metal surfaces [19], and thus would correspond to almost the same $\theta_{*}$ opt value from the equation $\theta_{*}$ opt $=1-\alpha$. Consequently, a similar dissociation energy $E_{\mathrm{ad}}{ }^{\mathrm{opt}}$ is essential, as demonstrated in Fig. 5. In this situation, we plotted the general trend of the dissociative adsorption energies of $\mathrm{N}_{2}, \mathrm{CO}$, and $\mathrm{O}_{2}$ with the metal position in the periodic table (Fig. 5), which clearly shows the location of the best catalyst by the intersection with

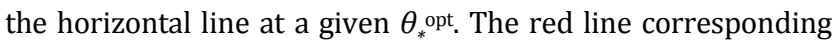
to $\mathrm{N}_{2}$ and $\mathrm{CO}$ dissociation is higher than that of $\mathrm{O}_{2}$ dissociation (blue line), reflecting a known fact that $\mathrm{N}_{2}$ and $\mathrm{CO}$ are harder to dissociate than $\mathrm{O}_{2}$. Therefore, from the intersection point (Fig. 5 ), it is evident that the optimal catalyst for CO or NO oxidation should be more noble than that for $\mathrm{NH}_{3}$ synthesis or the $\mathrm{CO}$ methanation reaction. It is worth noting that with a reasonable approximation in our equation, there should be a range for $E_{\text {ad }}{ }^{\text {opt }}$ (gray shaded region in Fig. 5).

Finally, it is worth noting that we also considered the catalytic model involving two surface species incorporated in one elementary step (i.e., $\mathrm{R}(\mathrm{g})+2^{*} \rightarrow 2 \mathrm{I}^{*} \rightarrow \mathrm{P}(\mathrm{g})+2^{*}$ ). In this case, the model can still be solved analytically, but it is too complicated to show. The numerical simulation result gives a very similar conclusion, further verifying our results.

\section{Brief review of recent applications of the volcano curve in catalyst screening}

Focusing on the use of the volcano curve in catalyst screening, we briefly discuss some of the latest examples of electro- catalytic conversion (the hydrogen evolution reaction (HER) and dye-sensitized solar cells (DSCs)).

\subsection{Identification of the optimal Pt catalyst for the hydrogen evolution reaction}

Traditionally, $\mathrm{H}_{2}$ evolution from water splitting by solar energy over $\mathrm{Pt} / \mathrm{TiO}_{2}$ is deemed to take place on metallic Pt nanoparticles. However, the effect of other Pt species dispersed on the surface of $\mathrm{TiO}_{2}$ is usually ignored. Toward the high efficient utilization of platinum in the HER of the water splitting process, Wang and Yang et al. elucidated the underlying mechanism of the HER and clarified the effect of the valence state and particle size of the Pt co-catalyst using the DFT-based volcano curve together with experimental characterization [46-48]. From DFT modeling and microkinetic analysis, they suggested that the atomic $\mathrm{H}$ adsorption energy can serve as an activity descriptor, and indicated that the activity of oxidized Pt species, highly dispersed Pt subnanoclusters [43], and even single atoms embedded in the $\mathrm{TiO}_{2}$ surface [44] are located much closer to the volcano peak than metallic Pt nanoparticles (Fig. 6(a)), revealing the key catalytic role of oxidized Pt species in the $\mathrm{Pt} / \mathrm{TiO}_{2}$ hydrogen evolution photocatalyst [46]. In particular, motivated from the above understanding, they also proposed a new oxidized PtO co-catalyst to efficiently promote the HER and inhibit the reverse $\mathrm{H}_{2}$ oxidation reaction [48].

\subsection{Rational screening of the counter electrode material for dye-sensitized solar cells}

DSCs are a way of efficiently harnessing solar energy. The discovery of efficient non-platinum counter electrode (CE) material to catalyze triiodide electroreduction was important for its large-scale application. To avoid trial-and-error tests, a general framework for screening CE material is urgently required. With a two-step kinetic model, Hou et al. [14] successfully used the adsorption energy of iodine as a descriptor to evaluate the

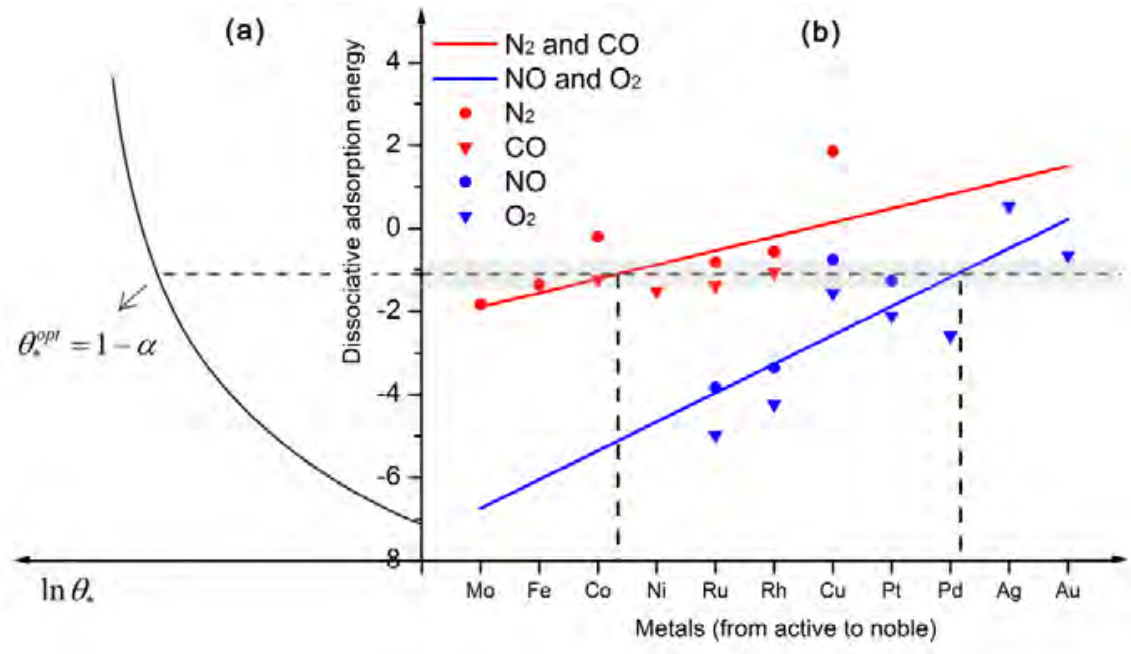

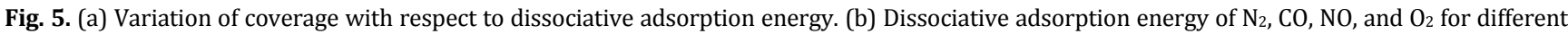
metals, which are ordered by the scale of their $d$-band center [45]. The red and blue lines were fitted by data on the stepped surface of various transition metals from Ref. [19]. 

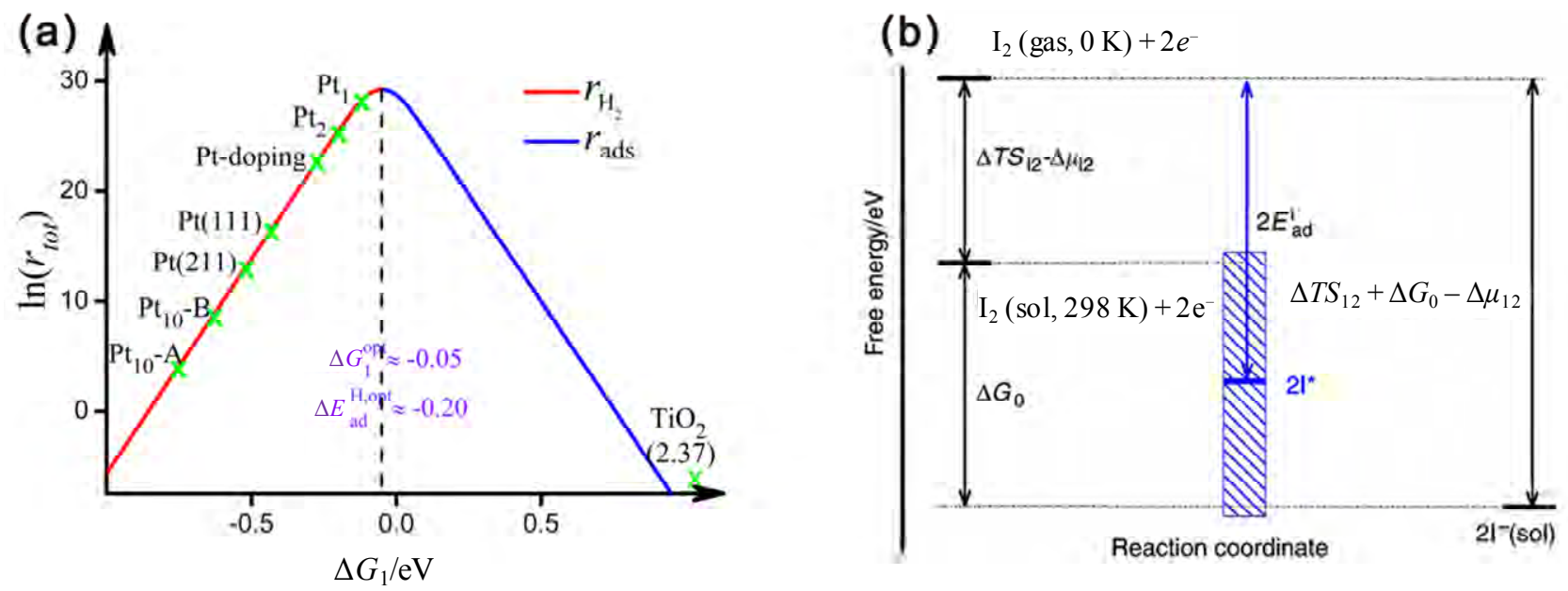

Fig. 6. (a) Volcano curve of the total reaction rate with respect to the Gibbs free energy of hydrogen adsorption $\left(\Delta G_{1}\right)$ of the HER for various Pt species (b); Range for suitable electrodes for DSCs in terms of the adsorption energy of iodine. Reprinted with permission from Refs. [46] and [14]. Copyright 2013, Royal Chemical Society and Copyright 2013, Nature Publishing Group.

activity variation. In Fig. 6(b), the catalysts in the blue area are "good catalysts" with relatively high activity. Yang et al. gave this area a physical picture by investigating the peak position of the volcano curve at adsorption and desorption determining circumstance [25]. Guided by this search criterion, they predicted and verified the activity of the different crystal planes of Pt $((111)>(411)>(100))$ [49], facilitating the shape-controlled synthesis of Pt nanocrystals and reducing the amount of Pt used. More significantly, by high-throughput simple adsorption energy calculations of a vast number of candidate materials, they predicted the highly efficient rust $\left(\alpha-\mathrm{Fe}_{2} \mathrm{O}_{3}\right)$ and $\mathrm{RuO}_{2}$ electrodes $[14,50]$. Furthermore, this criterion also guided the rational modification of inert indium oxide $\left(\operatorname{In}_{2} \mathrm{O}_{3}\right)$ by interstitially doping heteroatom $\mathrm{N}$ to tune its adsorption strength to the iodine atom [51].

\section{Conclusions and perspective}

In summary, a self-consistent mathematical analysis of the origin of the volcano curve was performed using a two-step kinetic model. We analytically proved the existence of the volcano curve in heterogeneous catalysis from a mathematical perspective, revealing the crucial role of the number of free sites. Conceptually, the rapid occupation of the active sites with increasing adsorption strength, which is defined as the self-poisoning effect, results in a slow adsorption rate and is the essential cause of the volcano curve. Some interesting implications for catalyst screening and practical applications of volcano-curve-based models are also discussed and reviewed. The concept of the volcano curve was proposed half of a century ago. Modern kinetic analysis and the development of computational chemistry have allowed us to obtain a deeper understanding of the volcano curve and facilitated its use in real catalytic processes. However, some aspects of the volcano curve are still not completely understood, despite the discussions given above. Some challenging questions still remain to be answered: Is there a simple routine to determine the optimal ad- sorption energy? How can we describe the kinetics of a multiphase catalyst? These issues deserve further attention in the future.

\section{Acknowledgments}

Prof. Hu thanks the Chinese Government for the "Thousands Talents" program.

\section{References}

[1] Norskov J K, Bligaard T, Rossmeisl J, Christensen C H. Nat Chem, 2009, 1: 37

[2] Norskov J K, Bligaard T. Angew Chem Int Ed, 2013, 52: 776

[3] Grabow L C. In: Asthagiri A, Janik M J ed. Computational Catalysis. Cambridge: The Royal Society of Chemistry, 2014. 1

[4] Balandin A A. Adv Catal, 1958, 10: 96

[5] Balandin A A. Adv Catal, 1969, 19: 1

[6] Bligaard T, Nørskov J K, Dahl S, Matthiesen J, Christensen C H, Sehested J. J Catal, 2004, 224: 206

[7] Dumesic J A, Rudd D F, Aparicio L M, Rekoske J E, Treviño A A. The Microkinetics of Heterogeneous Catalysis. Washington: American Chemical Society, 1993

[8] Trasatti S.J Electroanal Chem Interf Electrochem, 1972, 39: 163

[9] Jacobsen C J H, Dahl S, Clausen B S, Bahn S, Logadottir A, Nørskov J K. J Am Chem Soc, 2001, 123: 8404

[10] Toulhoat H, Raybaud P. J Catal, 2003, 216: 63

[11] Quaino P, Juarez F, Santos E, Schmickler W. Beilstein J Nanotechnol, 2014, 5: 846

[12] Liu Z-P. Pure Appl Chem, 2004, 76: 2069

[13] Becke A D. J Chem Phys, 2014, 140: 18A301

[14] Hou Y, Wang D, Yang X H, Fang W Q Zhang B, Wang H F, Lu G Z, Hu P, Zhao H J, Yang H G. Nat Commun, 2013, 4: 1583

[15] Medford A J, Wellendorff J, Vojvodic A, Studt F, Abild-Pedersen F, Jacobsen K W, Bligaard T, Norskov J K. Science, 2014, 345: 197

[16] Chorkendorff I, Niemantsve J W. Concepts of Modern Catalysis and Kinetics. Weinheim: Wiley-VCH, 2003

[17] Honkala K, Hellman A, Remediakis I N, Logadottir A, Carlsson A, Dahl S, Christensen C H, Nørskov J K. Science, 2005, 307: 555 


\title{
Graphical Abstract
}

Chin. J. Catal., 2015, 36: 1596-1605 doi: 10.1016/S1872-2067(15)60875-0

\section{Catalyst screening: Refinement of the origin of the volcano curve and its implication in heterogeneous catalysis}

Yu Mao, Jianfu Chen, Haifeng Wang*, P. Hu

East China University of Science and Technology, China;

The Queen's University of Belfast, United Kingdom

A self-consistent mathematic elucidation of the origin of volcano curve was conducted by a two-step kinetic model analytically, and some interesting guidelines for catalyst design are discussed during our derivation.

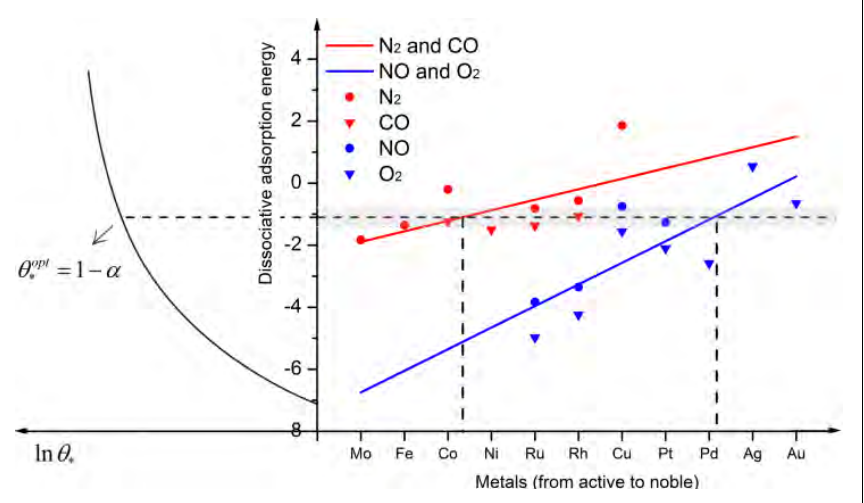

[36] Wang H F, Guo Y L, Lu G Z, Hu P. J Chem Phys, 2009, 130: 224701

[37] Dumesic J A. J Catal, 2001, 204: 525

[38] Dumesic J A. J Catal, 1999, 185: 496

[39] Bligaard T, Nørskov J K. In: Nilsson A, Pettersson L G M, Nørskov J K. ed. Chemical Bonding at Surface and Interface. Amsterdam: Elsevier, 2008. 255

[40] Ichikawa S. Chem Eng Sci, 1990, 45: 529

[41] Boisen A, Dahl S, Nørskov J K, Christensen C H. J Catal, 2005, 230: 309

[42] Kozuch S, Shaik S. J Phys Chem A, 2008, 112: 6032

[43] Vojvodic A, Medford A J, Studt F, Abild-Pedersen F, Khan T S, Bligaard T, Nørskov J K. Chem Phys Lett, 2014, 598: 108

[44] Liu H C, Wang H, Shen J H, Sun Y, Liu Z M. React Kinet Catal Lett, 2008, 93: 11

[45] Ruban A, Hammer B, Stoltze P, Skriver H L, Nørskov J K. J Mol Catal A, 1997, 115: 421

[46] Xing J, Jiang H B, Chen J F, Li Y H, Wu L, Yang S, Zheng L R, Wang H F, Hu P, Zhao H J, Yang H G. J Mater Chem, 2013, 1: 15258

[47] Li Y H, Xing J, Chen Z J, Li Z, Tian F, Zheng L R, Wang H F, Hu P, Zhao H J, Yang H G. Nat Commun, 2013, 4: 2500

[48] Xing J, Chen J F, Li Y H, Yuan W T, Zhou Y, Zheng L R, Wang H F, Hu P, Wang Y, Zhao H J, Wang Y, Yang H G. Chem Eur J, 2014, 20 : 2138

[49] Zhang B, Wang D, Hou Y, Yang S, Yang X H, Zhong J H, Liu J, Wang H F, Hu P, Zhao H J, Yang H G. Sci Rep, 2013, 3: 1836

[50] Hou Y, Chen Z P, Wang D, Zhang B, Yang S, Wang H F, Hu P, Zhao H J, Yang H G. Small, 2014, 10: 484

[51] Zhang B, Zhang N N, Chen J F, Hou Y, Yang S, Guo J W, Yang X H, Zhong J H, Wang H F, Hu P, Zhao H J, Yang H G. Sci Rep, 2013, 3: 3109

\section{催化剂篮选: 火山型曲线成因理论解析及其在多相催化中的应用}

\author{
毛 羽 ${ }^{\mathrm{a}}$, 陈建富 ${ }^{\mathrm{a}}$, 王海丰 ${ }^{\mathrm{a},}{ }^{*}$, 胡培君 ${ }^{\mathrm{a}, \mathrm{b}}$ \\ a华东理工大学计算化学中心, 工业催化研究所, 上海200237 \\ ${ }^{b}$ 英国贝尔法斯特女王大学化学化工学院, 英国贝尔法斯特BT9 $5 \mathrm{AG}$
}

\begin{abstract}
摘要: 多相催化对于现代社会来说具有极其重要的意义, 催化剂的理性设计/篮选是现代催化化学研究者的一个重要的目标. 其 中, 火山型曲线是一个的重要工具. 它指出对于一个催化反应来说, 其催化活性针对关键物种吸附能来说呈一条先上升后下降的 曲线, 要求最佳催化剂对中间体的吸附能不能太高也不能太低. 近几十年来, 密度泛函理论等第一性原理计算方法的发展让许多 催化剂表面反应微观物理量的计算成为了可能, 这极大地拓展了火山型曲线的应用范围.
\end{abstract}


然而, 对于火山型曲线根源的解释, 人们却并非了解得十分清楚; 一些基本科学概念的理解很多还是基于经验性的Sabatier原 理: 吸附太弱不利于吸附、太强不利于脱附. 针对该问题的科学解析, 本文进行了详细的动力学探究, 试图以完全数学解析的方式 回答催化反应中火山型曲线的必然存在性、产生根源及在催化活性预测中的内涵. 本文采用了两步催化模型以及微动力学来进 行速率方程的推导, 并考虑BEP关系(基元反应的能垒与其反应焓存在线性关系)的应用, 最终将整体反应速率转化为中间体吸附 能相关的单值函数. 基于对该函数的系列推导和分析, 得到如下基本结论:

(1)从数学上以一个完全的解析形式证明了催化反应中火山型曲线的存在.

(2)通过对比催化反应与与之对应的气相反应, 我们证明了: 若无催化剂参与反应, 则火山型曲线不会产生; 由于催化剂表面 的参与, 随着催化剂吸附能力的增强, 其表面会因为吸附作用而被占据毒化, 导致反应速率存在一个最大值, 即形成火山型曲线. 从概念上讲, 火山型曲线的根源是由“吸附过程引发表面活性位占据”这一自毒化效应造成的, 它的存在可能体现为多相催化的基 本属性.

(3)数值模拟解析展示了表面反应与气相反应的区别, 印证了我们的数学解析结论. 同时, 通过一定的简化, 我们对火山型曲 线中各部分的斜率进行了研究. 结果发现, 对于吸附决速过程, 催化反应和气相反应斜率相同, 其差别主要出现在脱附决速过程. 在此阶段由于吸附能过大, 表面被毒化, 表面反应速率开始下降; 而气相反应的速率依然上升.

(4)表面反应速率方程的分解和简化结果表明, 最佳催化剂在反应中的空活性位点覆盖度和其BEP关系的斜率存在内在关联 关系 $\left(\theta_{*}{ }^{\mathrm{opt}}=1-\alpha\right)$, 据此讨论了其在催化剂寻优过程中的意义. 尝试解释了(a)合成氨反应中正逆反应所需最佳催化剂不同的现象; (b)合成氨或 $\mathrm{CO}$ 甲烷化反应最佳催化剂为前过渡金属、而 $\mathrm{CO} / \mathrm{NO}$ 氧化等为后过渡金属这一典型催化现象的物理图像.

最后, 针对火山型曲线理论框架在实际催化剂理论篮选寻优中的应用, 我们简要综述了本课题组近年来在光解水制氢 Pt基助 催化剂和染料敏化太阳能电池的对电极材料设计方面的理论进展.

关键词: 火山型曲线; 多相催化; 密度泛函理论; 微观动力学; 催化剂篮选; 两步模型

收稿日期: 2015-04-01. 接受日期: 2015-04-27. 出版日期: 2015-09-20.

*通讯联系人. 电话: (021)64253453; 传真: (021)64253457; 电子信箱: hfwang@ecust.edu.cn

基金来源：国家重大科学计划研究项目(2013CB933201); 国家自然科学基金(21303052, 21333003); 中央高校基本科研业务费专 项资金(222201314035); 上海市自然科学基金(12ZR1442600); 上海市青年科技启明星计划(14QA1401100); 上海市晨光计划 (13CG24);

本文的英文电子版由Elsevier出版社在ScienceDirect上出版(http://www.sciencedirect.com/science/journal/18722067). 